\title{
Acute Effect of A Judo Contest on Muscular Performance Parameters And Physiological Response
}

\author{
Víctor Serrano-Huete (Corresponding author) \\ Didactics of Musical, Plastic and Corporal Expression. Universidad de Jaén, Campus Las Lagunillas s/n. 23071 Jaén, SPAIN \\ E-mail: victorsh1981@hotmail.com \\ Pedro A. Latorre-Román \\ Department of Didactics of Musical, Plastic and Corporal Expression. Universidad de Jaén, Campus Las Lagunillas s/n. 23071 Jaén, SPAIN \\ E-mail: platorre@ujaen.es \\ Felipe García-Pinillos \\ Didactics of Musical, Plastic and Corporal Expression. Universidad de Jaén, Campus Las Lagunillas s/n. 23071 Jaén, SPAIN \\ E-mail: fgpinill@ujaen.es \\ José A. Morcillo Losa \\ Didactics of Musical, Plastic and Corporal Expression. Universidad de Jaén, Campus Las Lagunillas s/n. 23071 Jaén, SPAIN \\ E-mail: jamlosa@ujaen.es \\ Rafael Moreno-Del Castillo \\ Didactics of Musical, Plastic and Corporal Expression. Universidad de Jaén, Campus Las Lagunillas s/n. 23071 Jaén, SPAIN \\ E-mail: rmoreno@ujaen.es \\ Juán A. Párraga-Montilla \\ Didactics of Musical, Plastic and Corporal Expression. Universidad de Jaénm, Campus Las Lagunillas s/n. 23071 Jaén, SPAIN \\ E-mail: jparraga@ujaen.es
}

Received: 03-05- 2016

Accepted: 25-06- 2016

Published: 31-07- 2016

doi:10.7575/aiac.ijkss.v.4n.3p.24

URL: http://dx.doi.org/10.7575/aiac.ijkss.v.4n.3p.24

\begin{abstract}
Background: It is necessary to know accurately the physical effects of judo contest on athletes in order to quantify how successive judo bouts impair muscular performance parameters and physiological response associated with the aim to create specific training programs that take the demands of judo bout into account. Purpose: The purpose of current study was to characterise the evolution of muscular performance parameters and physiological response during a judo contest. Methods: Twenty-nine men performed five 5-minute bouts with 15 minutes of passive rest. Immediately after the bouts, some muscular performance parameters and physiological variables were measured, in this order: Borg's rate of perceived exertion (RPE), maximal dynamic strength in upper body (MDS), countermovement jump (CMJ), dominant (DHS) and non-dominant handgrip isometric strength (NDHS). Lactate (LAC) was measured 3 minutes after each bout and 1 minute before the next too). Heart rate (HR) was monitored during the contest. ANOVA to compare baseline test data and successive bouts was used. Results: ANOVA revealed significant differences in $H_{\mathrm{mean}}$ $(p=0.045)$, LAC $(p<0.001)$ and in RPE $(p<0.001)$. A decrease in NDHS $(p<0.001)$, DHS $(p<0.001)$, MDS $(p<0.001)$ was found. Some significant correlations were found between NDHS and $\triangle \mathrm{MPV}(\mathrm{r}=0.368, \mathrm{p}=0.050), \Delta \mathrm{MS}(\mathrm{r}=0.369$, $\mathrm{p}=0.050)$ and $\triangle \mathrm{MXS}(\mathrm{r}=0.405, \mathrm{p}=0.029)$; between DHS and $\Delta \mathrm{LACb}(\mathrm{r}=0.430, \mathrm{p}=0.020), \Delta \mathrm{MXS}(\mathrm{r}=0.379, \mathrm{p}=0.043)$, $\Delta \mathrm{MP}(\mathrm{r}=0.369, \mathrm{p}=0.050)$ and $\triangle \mathrm{RPE}(\mathrm{r}=0.456, \mathrm{p}=0.013)$; between $\mathrm{CMJ}$ and $\Delta \mathrm{PM}(\mathrm{r}=0.381, \mathrm{p}=0.041), \Delta \mathrm{PMX}(\mathrm{r}=0.417$, $\mathrm{p}=0.024), \Delta \mathrm{FM}(\mathrm{r}=0.423, \mathrm{p}=0.022)$ and $\Delta \mathrm{DHS}(\mathrm{r}=0.348, \mathrm{p}=0.040)$. These results show a high decrease of muscular performance parameters and an increase of physiological parameters, specially between baseline test and postbout 5 , but gradual between all bouts. Conclusion: Judo contest can be considered a high intensity exercise, due to high levels of physiological parameters and the decrease in force production obtained.
\end{abstract}

Keywords: judo contest, bouts, muscular performance parameters, physiological response, physiological parameters, fatigue 


\section{Introduction}

\subsection{Introduce the problem}

It is well known that strength and other physiological capacities are good predictors of performance in a judo competition (Franchini, Artioli, \& Brito, 2013; Franchini, Miarka, Matheus, \& del Vecchio, 2011). Good muscular strength and endurance are required (Daniele Detanico, Dal Pupo, Franchini, \& Dos Santos, 2015; Franchini, Miarka, et al., 2011), particularly during grappling disputes where the aim is to become unstable to opponent. High muscle power is also needed for throwing techniques involving lower and upper body muscle groups (D. Detanico, Dal Pupo, Franchini, \& Dos Santos, 2012; Franchini, Del Vecchio, Matsushigue, \& Artioli, 2011).

Nowadays, judo can be framed as a combat sport with a grip on a judogi (judo kimono) (Bonitch-Góngora, BonitchDomínguez, Padial, \& Feriche, 2012), due to the fact that it permits the use of specific judo techniques and hindering of the opponent's actions during a 5-minute period, unless an ippon is scored (at the same time, the bout ends). The minimum period of recovery between matches is 15 minutes, established by the International Judo Federation (IJF). Thus, successive matches produce fatigue and cause considerable deterioration in physical capabilities (Iglesias, Clavel, Dopico, \& Tuimil, 2003), which results in deterioration in performance during these matches (Bonitch-Góngora et al., 2007). Although judo is a discipline that requires complex skills and tactical excellence, conditional capacities such as maximal isometric and dynamic strength also play a key role (Bonato et al., 2014). For this reason, in a judo contest with successive judo matches, it involves physiological, strength, metabolic and technical or tactical variables (D. Detanico et al., 2012; Franchini et al., 2013; Franchini, Del Vecchio, et al., 2011) that cause a higher fatigue rate (Daniele Detanico et al., 2015).

\subsection{Studies about judo contest. Review}

There are some researches on the physical capacities required for judo. Most of the studies have been carried out in laboratory conditions (Ache Dias et al., 2012; Bonitch-Góngora, Almeida, Padial, Bonitch-Domínguez, \& Feriche, 2013; Franchini et al., 2013; Franchini, Sterkowicz, Szmatlan-Gabrys, Gabrys, \& Garnys, 2011), and the findings might not be generalised to the specific demands of real competitive situations. It is important to quantify how successive judo matches affect strength and physiological variables associated with the level of judo performance in order to create training programmes that take the demands of judo competition into consideration (Franchini, Brito, Fukuda, \& Artioli, 2014).

The effects of some judo matches have been obtained in some studies (Bonitch-Góngora et al., 2013; E Carballeira, Iglesias, \& Dopico, 2008) on fatigue parameters in the upper and lower limbs (Ache Dias et al., 2012; BonitchDomínguez, Bonitch-Góngora, Padial, \& Feriche, 2010; Bonitch-Góngora et al., 2012; Daniele Detanico et al., 2015). As for the physiological response, some previous studies have studied the effect of successive judo matches on variables such as HR (Bonitch-Góngora et al., 2012; Franchini, de Moraes Bertuzzi, Takito, \& Kiss, 2009), LAC (Bonitch-Domínguez et al., 2010; Franchini et al., 2013, 2009; Franchini, Del Vecchio, et al., 2011; Franchini, Miarka, et al., 2011) or perceived exertion (RPE) (Bonato et al., 2014; Bonitch-Domínguez et al., 2010; E Carballeira et al., 2008; Dixon, Deitrick, Pierce, Cutrufello, \& Drapeau, 2005).

\subsection{Purpose of the study.}

Our problem statement in this study it is need to known the specific demands of judo contest mostly on fatigue and muscular performance. The novelty and significance of this study lies in the attempt to assess and link physiological response of fatigue with muscular performance parameters on athletes in a whole judo contest. The main purpose of the study was to characterize the evolution of muscular performance parameters and physiological response during a judo contest.

\section{Material and Methods}

\subsection{Participants}

Twenty-nine male judo athletes (age: $20.95 \pm 3.19$ years; weight: $74.43 \pm 8.53 \mathrm{~kg}$; height: $174.0 \pm 4.6 \mathrm{~cm}$; body mass index (BMI): $24.60 \pm 2.03 \mathrm{~kg} / \mathrm{m}^{2}$; body fat: $11.80 \pm 5.55 \%$; muscle mass: $62.27 \pm 7.08 \%$ ) voluntarily participated in this study. After receiving detailed information on the objectives and procedure, participants provided written informed consent in accordance with the ethical standards established the World Medical Association's Declaration of Helsinki (2008). Subjects less than 18 years old had to provide this informed consent signed by their parents. The study was approved by the local ethics committee and was conducted according to the European Community's guidelines for good clinical practice (111/3976/88; July 1990) and the Spanish legal framework for clinical research on humans (Real Decreto $561 / 1993$ on clinical trials). All participants were medallists in the Spanish or Poland National Championship in several age categories and had at least 10 years of experience of judo and 4 years of experience in judo competitions. Participants trained at least 8 hours per week and had not been injured for more than one week in the 3 months before the study.

\subsection{Procedures}

This was a repeated measures study. A simulated judo contest consisting of 5 five-minute matches (5 x 5-min) to examine judo performance across successive matches was used. If an ippon was scored, the match continued until the end of the time. Matches were separated by 15 minutes of passive rest, as in other simulated judo contest protocols (Bonitch-Domínguez et al., 2010; Bonitch-Góngora et al., 2012; Daniele Detanico et al., 2015; Franchini et al., 2009). 
We used the IJF round-robin format in which six contenders in a given weight category all fight each other. The contest for the assessment took place at the end of the mesocycle immediately before (approximately 2 weeks) an important tournament for participants. In order to assess the impact of judo contest on physiological and strength demands, some parameters were assessed immediately after each match: maximal dynamic strength (MDS), countermovement jump (CMJ), and handgrip isometric strength (HS). The rate of perceived exertion (RPE) was also recorded, and blood lactate samples (LAC) were collected before each match and at rest time before the next bout. The heart rate (HR) was recorded throughout the entire contest (Table 1). All these tests were performed during the first 3 minutes of rest time between bouts.

Table 1. Planning of measures and test procedures in data collection

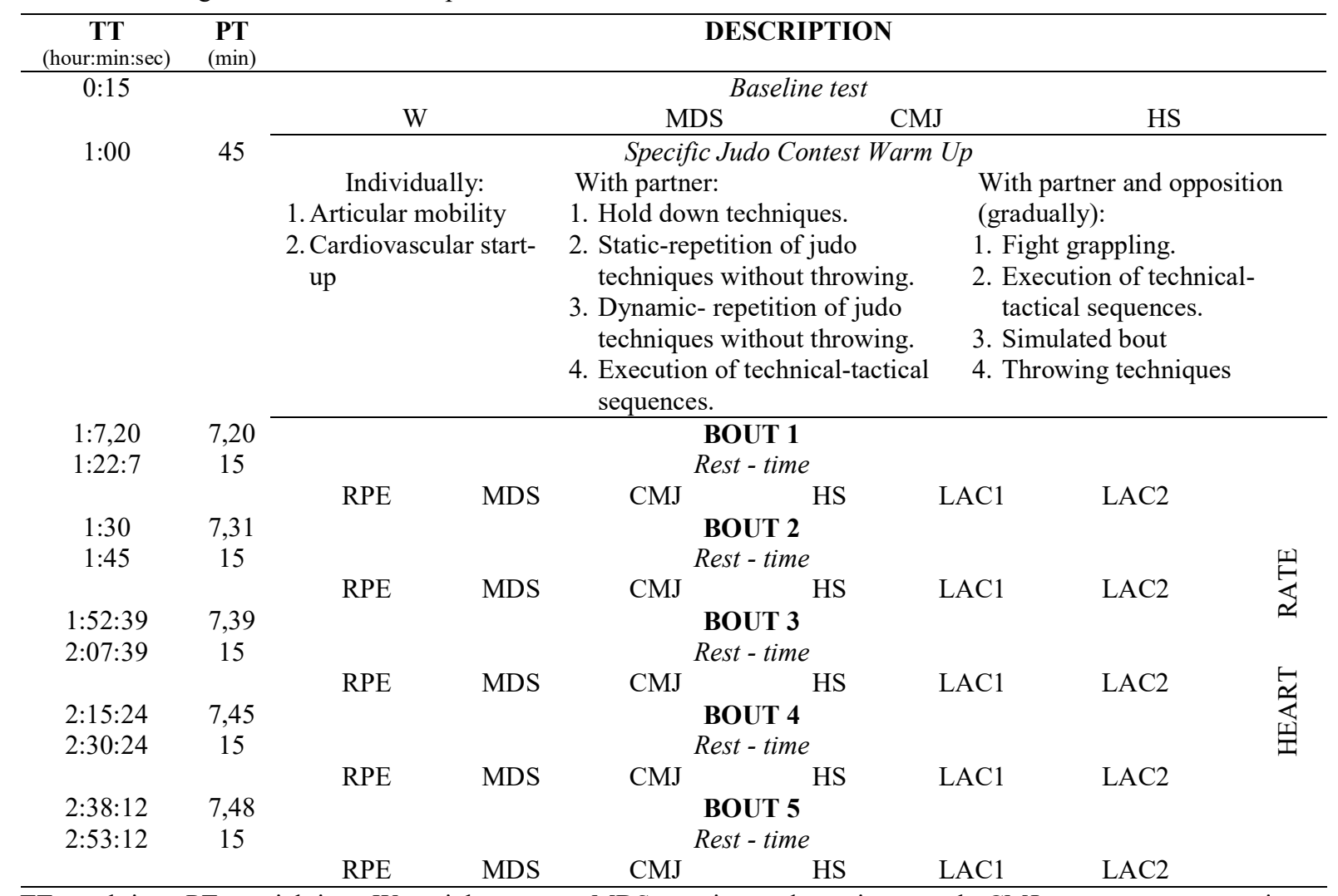

TT: total time; PT: partial time; W: weigh measure; MDS: maximum dynamic strength; CMJ: counter movement jump; HS: handgrip strength; HR: hear rate; RPE: rate of perceived exertion; LAC1: lactate 3min after a bout; LAC2: lactate $1 \mathrm{~min}$ before next bout.

Judo athletes were divided into weight groups so that there was less than $10 \%$ difference in body mass between athletes in a group (Daniele Detanico et al., 2015; Franchini et al., 2009). On the day of simulated judo contests, the subjects performed a test as a baseline or reference point for assessing the impact of successive matches before the specific judocompetition warm up. The protocol used in an official contest was replicated.

\subsubsection{Anthropometry and body composition}

Participants were weighed according to IJF weight protocol with a Tanita 330 S Portable (Tanita Corporation, Arlington Heights, IL, USA) to obtain body mass ( $\mathrm{kg})$, body fat and muscle mass variables $(\mathrm{kg}, \%)$. The procedure was the same as in other similar studies (Dixon et al., 2005). Height was measured using a Seca 213 Portable (Seca Deutschland, Hamburg, Germany).

\subsubsection{Physiological measures}

HR was monitored continuously throughout matches and recovery periods using the Polar Team ${ }^{2}$ System (Polar Electro Oy, Finland). HR mean (HRmean) and maximal (HRmax) during bouts (HRmeanB and HRmaxB) and rest times (HRmeanRT and HRmaxRT) were obtained. Immediately after each match the participants indicated their perceived level of exertion during the match using the 6-20 Borg Scale (Borg, 1982). To calculate LAC (mmol.1 ${ }^{-1}$ ), a drop of capillary blood was extracted carefully by a nurse (Shariat, Kargarfard, Danaee, \& Bahri Mohd Tamrin, 2015) and put into a reagent strip of a lactate analyser: Lactate $S c o u t \AA$, as in previous studies (Lopez-Grueso, Aracil, Sarabia, \& Montero, 2014). Blood samples after 3 minutes at the end of each bout (LACa) and 1 min before the next (LACb) were extracted. 


\subsubsection{Muscular performance measures}

CMJ was used to measure the strength of the lower body (Bosco, 1999), with the same protocols as those of other authors (Lehance, Binet, Bury, \& Croisier, 2009). Participants were experienced athletes who conduct different plyometric exercises in their daily training sessions. Moreover, to make sure the execution of the test conducted was correct, a familiarisation session was carried out. Subjects performed two attempts of CMJ, with a 15-s recovery period between them, with the best result being used for the statistical analysis. The CMJ was recorded using the OptoGait system (Microgate, Bolzano, Italy), which has been used in similar studies (Lehance et al., 2009).

A bench press exercise was used to calculate the following muscular performance parameters for the upper limbs: mean power velocity (MPV), mean strength (MS), maximum strength (MXS), mean power (MP) and maximum power (MXP) for the upper limbs. The T-Force Dynamic Measurement System (Ergotech, Murcia, Spain) was used to quantify bench press capacity, as in similar studies (Pareja-Blanco, Rodríguez-Rosell, Sánchez-Medina, Gorostiaga, \& González-Badillo, 2014). It is a dynamic system for assessing and training muscle strength and enables one to obtain a direct estimate of load shift velocity in each repetition. The system automatically recognises an eccentric-concentric phase as a repetition. The exercise was performed only once after each match to minimise fatigue for participants. This exercise was familiar to participants due to the fact that it is frequently used in physical training for combat sport (L. Sánchez-Medina, González-Badillo, Pérez, \& Pallarés, 2014). Participants were required to achieve an execution speed of at least $1 \mathrm{~m} / \mathrm{s}(60 \%-70 \%$ 1RM.) (Luis Sánchez-Medina \& Gonzalez-Badillo, 2011) to determine the load for the next repetitions (González-Badillo, Rodríguez-Rosell, Sánchez-Medina, Gorostiaga, \& Pareja-Blanco, 2014).

A digital hand dynamometer (TKK 5101 Grip D; Takey, Tokyo, Japan) was used to record HS in kg, according to considerations in previous studies (Bonitch-Góngora et al., 2012; Franchini, Branco, Agostinho, Calmet, \& Candau, 2015; Iglesias et al., 2003). Optimum grip was adjusted according to the calibration formula given by Ruiz et al. (Ruiz et al., 2006). Participants were encouraged to achieve maximum handgrip isometric strength. Three 5-s trials were performed with the dominant hand (DHS) and non-dominant hand (NDHS), separated by 15 seconds of recovery; the best result was selected for the subsequent statistical analysis.

\subsection{Statistical Analysis}

The data were analysed using SPSS version 19.0 for Windows (SPSS, Inc., Chicago, IL, USA) and the significance level was set at $\mathrm{p} \leq 0.05$. The data are presented as means and SDs. Levene's test and the Shapiro-Wilk test was used to confirm that the data were normally distributed. A one-way repeated measures analysis of variance (ANOVA) was used to compare data between pre- and post-test. Bonferroni's test was used for post hoc assessments of pairwise differences. Ordinal data-RPE - were assessed using the nonparametric Friedman and Wilcoxon contrast test. Additionally, a Pearson correlation analysis was conducted. Increases of all variables with the difference between results in postmatch 5 and basal result were calculated $(\Delta)$.

\section{Results}

LAC values are presented in Figure 2. LACa levels increased during the successive bouts $(\mathrm{p}<0.001)$.

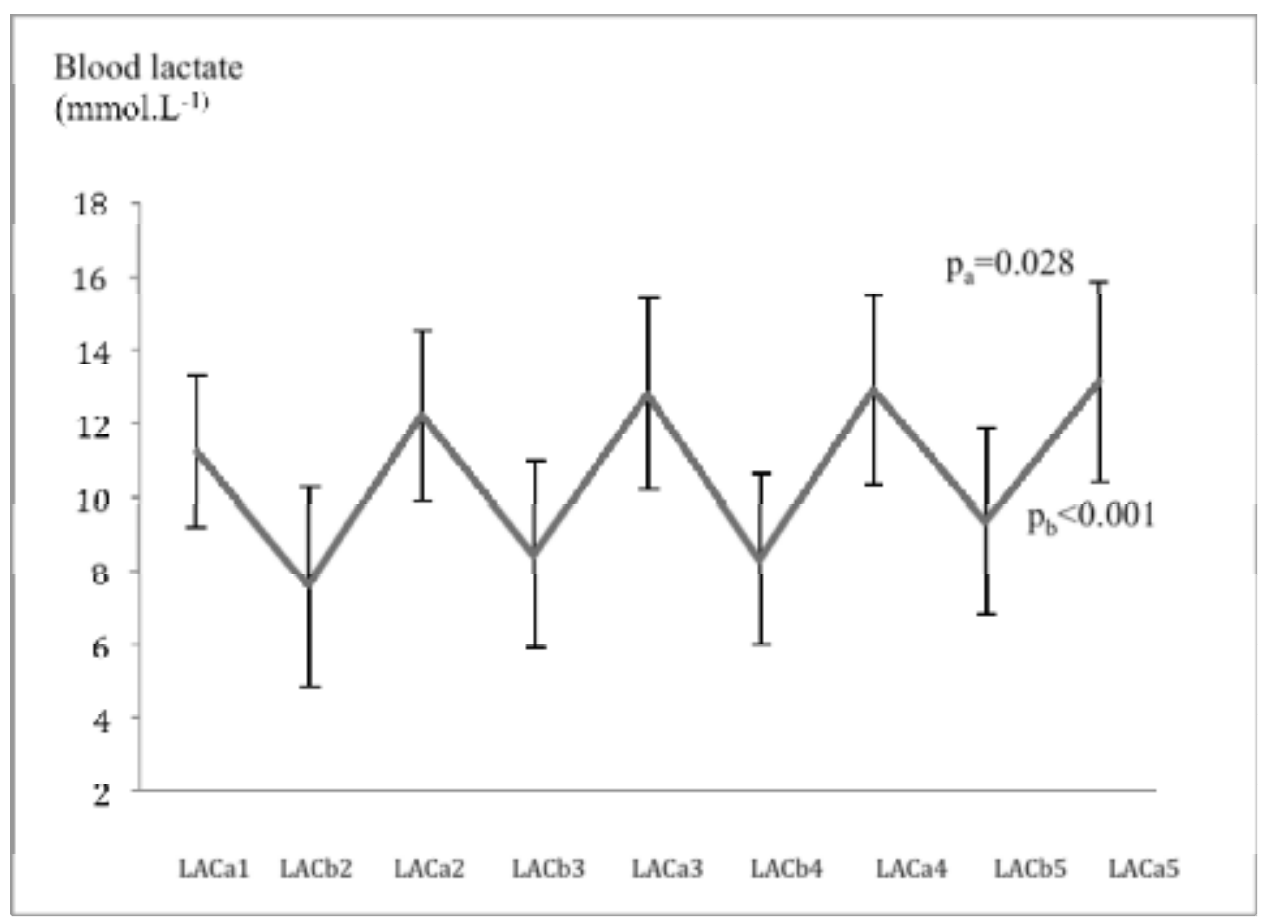

Figure 2. Blood lactate values during the contest. LACa: lactate measure taken $3^{\prime}$ after a bout; LACb: lactate measure taken 1' before a bout. $\mathrm{P}_{\mathrm{a}}$ : significance level of LACa; $\mathrm{P}_{\mathrm{b}}$ : significance level of LACb. 
Figure 3 shows the mean heart rate (HRmean) and maximum heart rate (HRmax) values. In HRmax, significant differences over the protocol with an increased heart rate during bouts $(\mathrm{HRb})(\mathrm{p}=0.018)$ and during rest times $(\mathrm{HRrt})$ $(\mathrm{p}=0.025)$ were obtained.

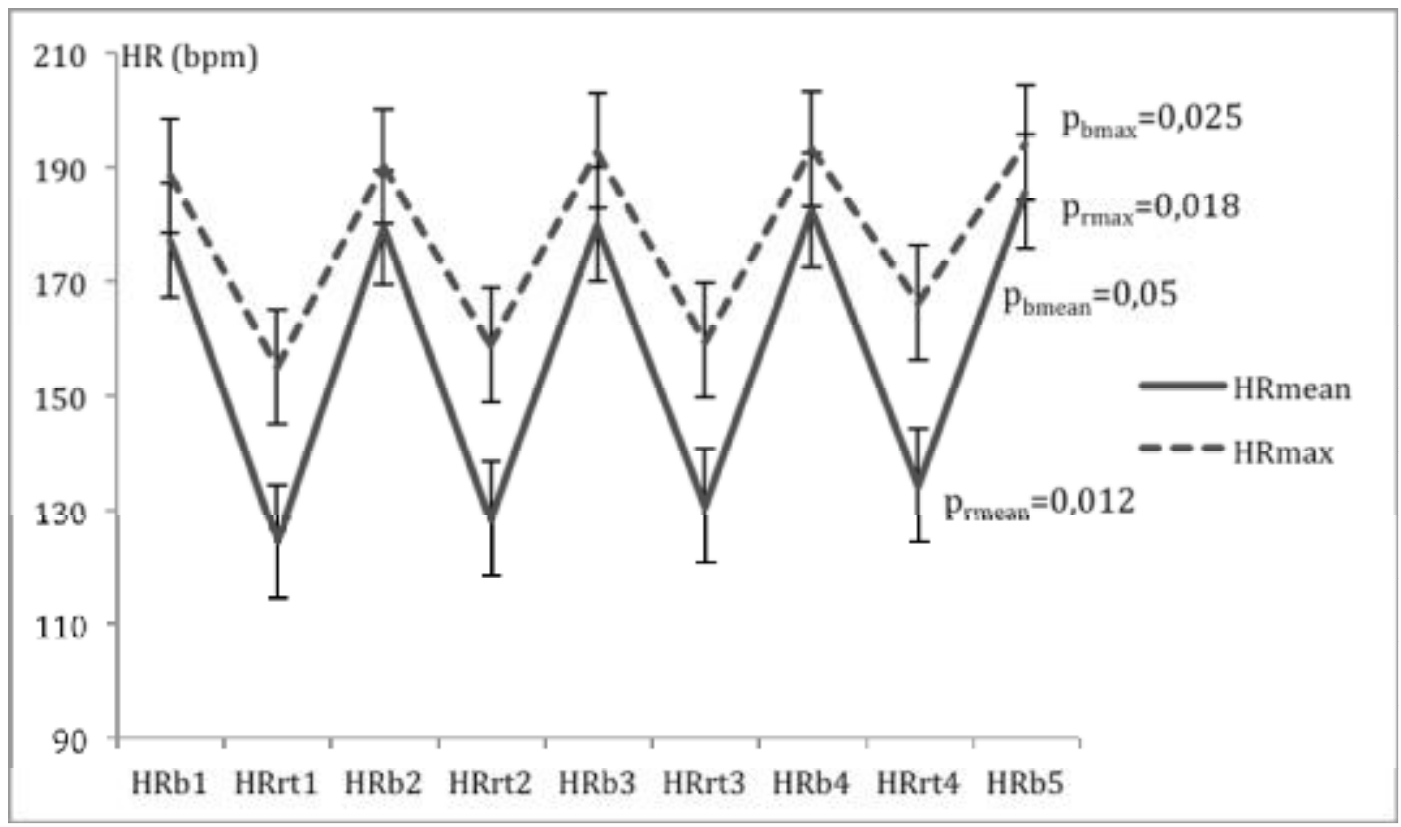

Figure 3. Heart response (bpm) during the contest. HR: heart rate; HRb: heart rate during a bout; HRrt: heart rate during recovery-time; BMP: beat per minute. HRmean: mean heart rate; HRmax: maximum heart rate; Pbmax: significance level of HRbmax; Prmax: significance level of HRrtmax; Pbmean: significance level of HRbmean; Prmean: significance level of HRrtmean.

Figure 4 shows RPE measures taken immediately after each bout (RPE). ANOVA revealed significant differences in RPE over the contest $(\mathrm{p}<0.001)$ with higher values throughout the contest.

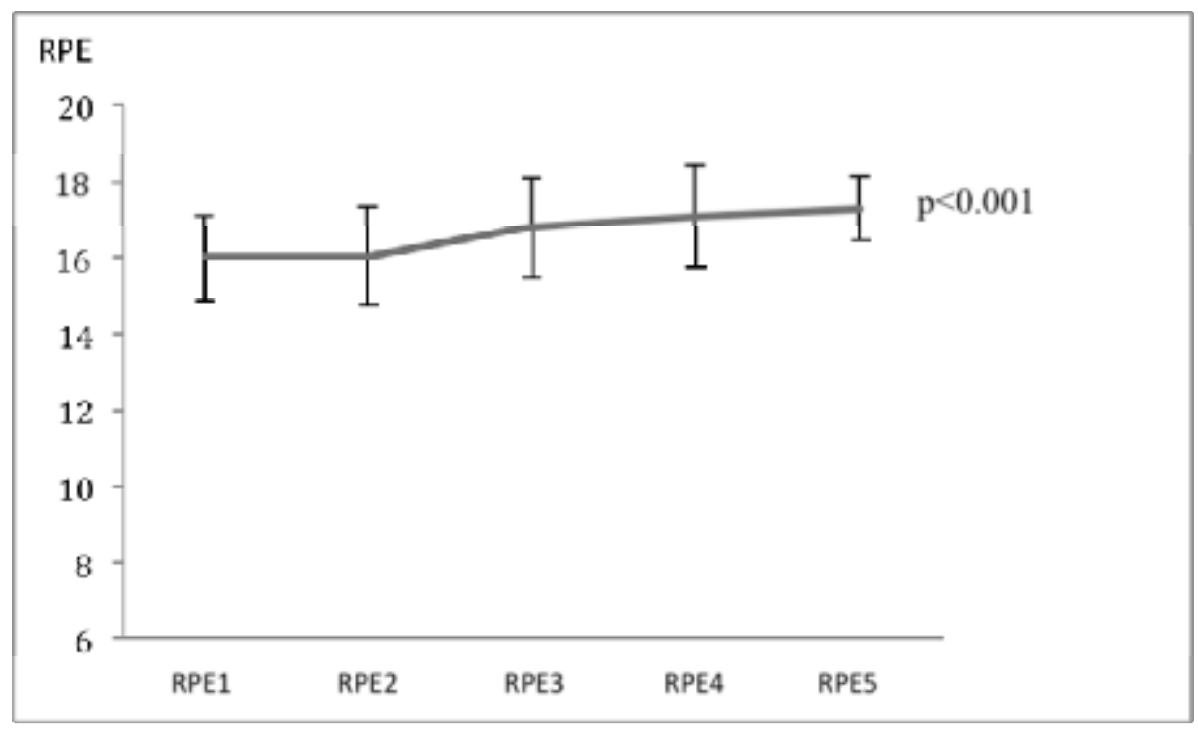

Figure 4. Rate of perceived exertion (RPE) after bouts.

Regarding HS performance, significant decreases during successive bouts either in DHS (49.22kgf \pm 5.48 in baseline test to $41.20 \mathrm{kgf} \pm 6.70$ after bout 5) and NDHS (47.19kgf \pm 5.10 in baseline test to $43.89 \mathrm{kgf} \pm 5.98$ after bout 5) were found $(\mathrm{p}<0.001)$. The Pearson test revealed significant correlations between NDHS and $\Delta \mathrm{MPV}(\mathrm{r}=0.368, \mathrm{p}=0.050), \Delta \mathrm{MS}$ $(\mathrm{r}=0.369, \mathrm{p}=0.050)$ and $\triangle \mathrm{MXS}(\mathrm{r}=0.405, \mathrm{p}=0.029)$. Significant correlations between DHS and $\Delta \mathrm{LACb}(\mathrm{r}=0.430$, $\mathrm{p}=0.020), \Delta \mathrm{MXS}(\mathrm{r}=0.379, \mathrm{p}=0.043), \Delta \mathrm{MP}(\mathrm{r}=0.369, \mathrm{p}=0.050)$ and $\triangle \mathrm{RPE}(\mathrm{r}=0.456, \mathrm{p}=0.013)$ were obtained.

As for CMJ, significant differences during all bouts $(35.36 \mathrm{kgf} \pm 4.66$ in baseline test to $31.813 \mathrm{kgf} \pm 4.37$ after bout 5$)$ were found $(\mathrm{p}<0.001)$. The Pearson correlation analysis revealed some significant correlations between CMJ and neuromuscular variables: $\Delta \mathrm{PM}(\mathrm{r}=0.381, \mathrm{p}=0.041), \Delta \mathrm{PMX}(\mathrm{r}=0.417, \mathrm{p}=0.024), \Delta \mathrm{FM}(\mathrm{r}=0.423, \mathrm{p}=0.022)$ and $\Delta \mathrm{DHS}$ $(\mathrm{r}=0.348, \mathrm{p}=0.040)$. 
Significant differences over the protocol in MPV $(0.97 \mathrm{kgf} \pm 0.09$ in baseline test to $0.81 \mathrm{kgf} \pm 0.13$ after bout 5) were obtained $(\mathrm{p}<0.001)$. The Pearson correlation analysis showed significant correlations with $\triangle \mathrm{RPE}(\mathrm{r}=-0.376, \mathrm{p}=0.044)$ and $\triangle \mathrm{LACb}(\mathrm{r}=0.437, \mathrm{p}=0.018)$. No significant changes $(\mathrm{p}=0.129)$ for MS during the contest were obtained. Significant correlations between MS and $\Delta \mathrm{DHS}(\mathrm{r}=0.369, \mathrm{p}=0.049)$ were found (there is a difference of $11.38 \mathrm{~N}$ between postbout 5 and baseline test only). MXS showed a decrease ( $746.71 \mathrm{kgf} \pm 144.69$ in baseline test to $691.77 \mathrm{kgf} \pm 132.38$ after bout 5) during the contest $(\mathrm{p}<0.001)$. Significant correlations between MXS and physiological variables $(\triangle \mathrm{RPE}: \mathrm{r}=0.376$, $\mathrm{p}=0.044 ; \Delta$ HRmeanb: $\mathrm{r}=0.405, \mathrm{p}=0.029)$ were found. About MP, significant differences during all bouts (409.06kgf \pm 69.76 in baseline test to $349.11 \mathrm{kgf} \pm 77.85$ after bout 5) were found $(\mathrm{p}<0.001)$. The Pearson test revealed significant correlations between MP and $\triangle \mathrm{RPE}(\mathrm{r}=0.528, \mathrm{p}=0.003)$. Significant differences in MXP (797.16kgf \pm 132.33 in baseline test to $692.04 \mathrm{kgf} \pm 125.08$ after bout 5 ) were found. ( $<0.001)$ The Pearson correlation analysis resulted in significant correlations with $\Delta \mathrm{HRmeanb}(\mathrm{r}=0.394, \mathrm{p}=0.034), \Delta \mathrm{LACb}(\mathrm{r}=0.415, \mathrm{p}=0.025)$ and $\Delta \mathrm{DHS}(\mathrm{r}=0.377, \mathrm{p}=0.044)$.

\section{Discussion}

The main aim of this study was to determine the evolution of muscular performance parameters and physiological response during a judo contest. According to results obtained, it could be related a judo contest with a decrease in strength production as upper and lower limb and on trunk strength. Increase of physiological markers indicated that bouts were development with a high intensity, similar to other studies (Bonitch-Góngora et al., 2012; Daniele Detanico et al., 2015; Franchini et al., 2013; Sbriccoli, Bazzucchi, Di Mario, Marzattinocci, \& Felici, 2007), and 15 minutes of recovery time between them was insufficient to return to baseline parameters.

One of the strengths of this study was the use of a judo contest situation, with the same operating protocol of an official contest. It was intended that physical efforts be the same or similar to an official contest, as indicated by high values of physiological markers. In addition, these physiological parameters and their impact on muscular response and strength production were related.

Few studies have recorded HR during bouts. Franchini et al. (Franchini et al., 2013) also observed an increase in cardiovascular stress during the course of a contest. Only one study (Sbriccoli et al., 2007) reported HR during a only bout (180 bpm \pm 11 ). No studies where HR was measured during successive bouts, as in our study (from $177.17 \mathrm{bpm}$ in bout 1 to $185.69 \mathrm{bpm}$ in bout 5) were found. With all of these considerations, it could be suggested that although judo requires only an intermittent effort, the high HRs of judo players indicate that judo places a high demand on the cardiovascular system, and training should reflect this.

LAC is reliably related with performance in judo bouts (Bonitch-Domínguez et al., 2010; Bonitch-Góngora et al., 2012; Franchini et al., 2013; Franchini, Del Vecchio, et al., 2011; Sbriccoli et al., 2007). As opposite results with our study, some research has indicated that LAC levels decrease during successive bouts (Bonitch-Domínguez et al., 2010; Bonitch-Góngora et al., 2012). A study in which LAC was measured before three bouts separated by $\sim 12$-min intervals reported that this recovery period was not sufficient to allow LAC levels to return to baseline (Thomas, Cox, LeGal, Verde, \& Smith, 1989), in the same line of current study. There was an increase in pre-bout LAC levels between successive bouts $\left(1.6 \pm 0.6 \mathrm{mmol}^{-1} \mathrm{l}^{-1} 3.1 \pm 1.9 \mathrm{mmol}^{-1}{ }^{-1} ; 4.3 \pm 2.1 \mathrm{mmol.1} \mathrm{l}^{-1}\right)$. These results indicate that the official minimum recovery time is not sufficient to return LAC to baseline levels. In this study, blood LAC values after bout simulations were $>10 \mathrm{mmol}^{-1} \mathrm{I}^{-1}$ indicating moderate to high demand on the glycolytic system. These values are, however, approximately $2-3$ mmol. $1^{-1}$ lower than levels after real competitions, suggesting that bout simulations impose lower glycolytic demand than real contest (Franchini et al., 2013). Another relevant finding as an earlier report (Bonitch, Ramirez, Femia, Feriche, \& Padial, 2005) was that the Borg scale (Borg, 1982) could be used to monitor metabolic and the cardiovascular stress during official judo contest. Bonitch et al. (Bonitch et al., 2005) found that LAC levels were significantly correlated with RPE, and concluded that ratings of RPE can be used to monitor cardiovascular stress during judo bouts.

This study revealed deterioration in HS in both hands over the course of successive bouts, similar results of a previous study reported a $12.7 \%$ decline in the strength of the dominant hand after one bout and a $15 \%$ decline after four bouts (Bonitch-Góngora et al., 2012). Another study (E Carballeira et al., 2008) reported a 5\% reduction in HS after the first match and a $15 \%$ reduction after the second bout. In the current study, correlations show that athletes with higher values of HS develop a high quantity of strength (mean and maximal), and this strength is obtained at a high velocity (especially with the non-dominant hand). In the dominant hand, athletes with higher values have a high rate of perceived exertion of the bout. The fact that there is no correlation between DHS and NDHS could be because both hands make different works with different efforts. For this reason, laterality has influence in the HS performance during a judo contest. It can be argued that isometric strength endurance is more relevant to performance in a real bout situation than maximal strength, since judokas use their grip almost continuously during a judo bout, whereas maximal strength is not maintained for a long time (Franchini, Sterkowicz, et al., 2011).

Only a few studies of MDS after judo bouts have obtained similar decreases to those observed in this study. One (Eduardo Carballeira \& Iglesias, 2007) found a decrease of more than 5\% in a bench press test after a bout. The authors concluded that a judo bout induces fatigue in flexor and extensor muscles. Similar decreases were found in this study after bout 1 (5.01\% in MPV and 5.30\% in MXP), and this percentage increased during the simulated judo context. This decline in MDS could indicate that the accumulation of fatigue over successive bouts reduces neuromuscular capabilities resulting in a reduction in strength during bouts. Correlations with some physiological parameters (RPE, LACb and HRmeanb) show that the most powerful athletes are most fatigued, too. 
There was a decrease in CMJ height relative to baseline. Other studies found similar reductions in CMJ height after three bouts (Daniele Detanico et al., 2015). These findings may be due to the high eccentric-concentric load on the lower limbs during judo-specific techniques (D. Detanico et al., 2012; Daniele Detanico et al., 2015) obtained higher baseline values than those observed in the current study in a study of Brazilian judo players (44.53 $\mathrm{cm} \pm 3.8)$ and observed reductions after the first and second bouts in a series, in the line of current study. Jump height is considered an absolute indicator of lower limb muscle power (Daniele Detanico et al., 2015) because it is independent of body size characteristics (Markovic \& Jaric, 2007). Successive measurements should thus provide a good indicator of lower limb fatigue, whether in training or over the course of several bouts. This kind of decline could affect power production and recovery. Correlations with other muscular performance parameters show that judo is a complete sport that develops not only upper but also lower limbs, as athletes who have high strength values in lower limb muscle power also have high strength values in MDS and HS.

\section{Conclusion}

Current study showed that judo contest amount to a high intensity exercise session that produces high levels of physiological parameters indicators of fatigue (LAC, HR, RPE, etc.) In relation to this aspect, the capacity of strength production obtained a significant decrease during the successive bouts of the contest. For these two reasons, 15-min of rest is not enough to return these parameters to baseline levels. Physical trainers and coaches should use all of this valuable information to design specific training programs for judo competition. Also, a high quantity of feedback will be proportionated as assessment of training at that moment.

\section{References}

Ache Dias, J., Wentz, M., Külkamp, W., Mattos, D., Goethel, M., \& Borges Júnior, N. (2012). Is the handgrip strength performance better in judokas than in non-judokas? Science and Sports, 27(3), 9-14.

Bonato, M., Rampichini, S., Ferrara, M., Benedini, S., Sbriccoli, P., Merati, G., ... Medica, E. M. (2014). Aerobic training program for the enhancements of HR and VO2 off-kinetics in elite judo athletes. The Journal of Sports Medicine and Physical Fitness, 55(11), 1277-84.

Bonitch-Domínguez, J., Bonitch-Góngora, J., Padial, P., \& Feriche, B. (2010). Changes in peak leg power induced by successive judo bouts and their relationship to lactate production. Journal of Sports Sciences, 28(14), 1527-1534.

Bonitch-Góngora, J. G., Almeida, F., Padial, P., Bonitch-Domínguez, J. G., \& Feriche, B. (2013). Maximal isometric handgrip strength and endurance differences between elite and non-elite young judo athletes. Archives of Budo, 9(4), 239-248.

Bonitch-Góngora, J. G., Bonitch-Domínguez, J. G., Feriche, B., Chirosa, I., Sánchez, C., Granados, M. Á., \& Padial, P. (2007). Análisis del comportamiento de la resistencia a la fuerza isométrica máxima de la musculatura prensora del antebrazo en judokas. Archivos Medicina del Deporte, 24(121), 358.

Bonitch-Góngora, J. G., Bonitch-Domínguez, J. G., Padial, P., \& Feriche, B. (2012). The effect of lactate concentration on the handgrip strength during judo bouts. Journal of Strength and Conditioning Research, 26(7), 1863-71. Retrieved from http://www.ncbi.nlm.nih.gov/pubmed/21986690

Bonitch, J., Ramirez, J., Femia, P., Feriche, B., \& Padial, P. (2005). Validating the relation between heart rate and perceived exertion in a judo competition. Medicina Dello Sport, 58(1), 23-28.

Borg, G. A. (1982). Psychophysical bases of perceived exertion. Medicine and Science in Sports and Exercise, 14 (5), 377-381.

Bosco, C. (1999). La evaluación de la fuerza con el test de Bosco. Barcelona: Paidotribo.

Carballeira, E., \& Iglesias, E. (2007). Acute effects of the judo fight: multiparametric analysis. European Journal of Human Movement. Asociación Española de Ciencias del Deporte, 19, 111-138.

Carballeira, E., Iglesias, E., \& Dopico, X. (2008). Análisis de los efectos agudos del enfrentamiento en judo, a través del estudio de la asociación entre parámetros metabólicos y mecánicos. Fitness \& Performance Journal, 7(4), $229-238$.

Detanico, D., Dal Pupo, J., Franchini, E., \& Dos Santos, S. G. (2012). Relationship of aerobic and neuromuscular indexes with specific actions in judo. Science and Sports, 27(1), 16-22.

Detanico, D., Dal Pupo, J., Franchini, E., \& Dos Santos, S. G. (2015). Effects of successive judo matches on fatigue and muscle damage markers. Journal of Strength and Conditioning Research, 29(4), 1010-6. http://doi.org/10.1519/JSC.0000000000000746

Dixon, C. B., Deitrick, R. W., Pierce, J. R., Cutrufello, P. T., \& Drapeau, L. L. (2005). Evaluation of the BOD POD and leg-to-leg bioelectrical impedance analysis for estimating percent body fat in National Collegiate Athletic Association Division III collegiate wrestlers. Journal of Strength and Conditioning Research, 19(1), 85-91.

Franchini, E., Artioli, G. G., \& Brito, C. J. (2013). Judo combat: time-motion analysis and physiology. International Journal of Performance Analysis in Sport, 13(3), 624-641.

Franchini, E., Branco, B. M., Agostinho, M. F., Calmet, M., \& Candau, R. (2015). Influence of Linear and Undulating Strength Periodization on Physical Fitness, Physiological, and Performance Responses to Simulated Judo Matches. Journal of Strength and Conditioning Research, 29(2), 358-367. 
Franchini, E., Brito, C. J., Fukuda, D. H., \& Artioli, G. G. (2014). The physiology of judo-specific training modalities. Journal of Strength and Conditioning Research, 28(5), 1474-81.

Franchini, E., de Moraes Bertuzzi, R. C., Takito, M. Y., \& Kiss, M. A. P. D. M. (2009). Effects of recovery type after a judo match on blood lactate and performance in specific and non-specific judo tasks. European Journal of Applied Physiology, 107(4), 377-383.

Franchini, E., Del Vecchio, F. B., Matsushigue, K. a., \& Artioli, G. G. (2011). Physiological profiles of elite judo athletes. Sports Medicine, 41(2), 147-166.

Franchini, E., Miarka, B., Matheus, L., \& del Vecchio, F. B. (2011). Endurance in judogi grip strength tests: Comparison between elite and non-elite judo players. Archives of Budo, 7(1), 1-4.

Franchini, E., Sterkowicz, S., Szmatlan-Gabrys, U., Gabrys, T., \& Garnys, M. (2011). Energy system contributions to the special judo fitness test. International Journal of Sports Physiology and Performance, 6(3), 334-343.

González-Badillo, J. J., Rodríguez-Rosell, D., Sánchez-Medina, L., Gorostiaga, E. M., \& Pareja-Blanco, F. (2014). Maximal intended velocity training induces greater gains in bench press performance than deliberately slower halfvelocity training. European Journal of Sport Science, (May 2014), 1-10.

Iglesias, E., Clavel, I., Dopico, X., \& Tuimil, J. L. (2003). Efecto agudo del esfuerzo específico de judo sobre diferentes manifestaciones de la fuerza y su relación con la frecuencia cardiaca alcanzada durante el enfrentamiento. RendimientoDeportivo.com, 6, 27.

Lehance, C., Binet, J., Bury, T., \& Croisier, J. L. (2009). Muscular strength, functional performances and injury risk in professional and junior elite soccer players. Scandinavian Journal of Medicine \& Science in Sports, 19(2), $243-51$. http://doi.org/10.1111/j.1600-0838.2008.00780.x

Lopez-Grueso, R., Aracil, A., Sarabia, J. M., \& Montero, C. (2014). Beta-alanine supplementation seems to increase physical performance and acute recovery in competitive judokas. European Journal of Human Movement, 33, $123-136$.

Markovic, G., \& Jaric, S. (2007). Is vertical jump height a body size-independent measure of muscle power? Journal of Sports Sciences, 25(12), 1355-1363. http://doi.org/10.1080/02640410601021713

Pareja-Blanco, F., Rodríguez-Rosell, D., Sánchez-Medina, L., Gorostiaga, E. M., \& González-Badillo, J. J. (2014). Effect of Movement Velocity during Resistance Training on Neuromuscular Performance. International Journal of Sports Medicine,35(11), 916-924.

Ruiz, J. R., España-Romero, V., Ortega, F. B., Sjöström, M., Castillo, M. J., \& Gutierrez, A. (2006). Hand Span Influences Optimal Grip Span in Male and Female Teenagers. Journal of Hand Surgery, 31(8), 1367-1372.

Sánchez-Medina, L., \& Gonzalez-Badillo, J. J. (2011). Velocity loss as an indicator of neuromuscular fatigue during resistance training. Medicine Science in sports and exercise. Medicine \& Science in Sports \& Exercise, 43(9), 17251734.

Sánchez-Medina, L., González-Badillo, J. J., Pérez, C. E., \& Pallarés, J. G. (2014). Velocity- and power-load relationships of the bench pull vsBench press exercises. International Journal of Sports Medicine, 35, $209-216$.

Sbriccoli, P., Bazzucchi, I., Di Mario, A., Marzattinocci, G., \& Felici, F. (2007). Assessment of maximal cardiorespiratory performance and muscle power in the Italian Olympic judoka. Journal of Strength and Conditioning Research, 21(3), 738-744.

Shariat, A., Kargarfard, M., Danaee, M., \& Bahri Mohd Tamrin, S. (2015). Intensive resistance exercise and circadian salivary testosterone concentrations among young male recreational lifters. Journal of Strength and Conditioning Research, 29(1), 151-158. http://doi.org/10.1519/JSC.0000000000000632

Thomas, S. G., Cox, M. H., LeGal, Y. M., Verde, T. J., \& Smith, H. K. (1989). Physiological profiles of the Canadian National Judo Team. Canadian Journal of Sport Sciences, 14(3), 142-147. 